\title{
CASE REPORT : THE MENTAL STATE DURING RECOVERY AFTER HEART ARREST DURING ANAESTHESIA
}

BY

\author{
HERBERT TURNER
}

The literature contains numerous references to cases in which arrest of the heart's action has occurred under anæsthesia, Bailey (1947), Sappenfield and Adriani (1947), and Noble (1947) being among the most recent. Most of the papers deal with methods of resuscitation, in particular cardiac massage, but apart from a report by Howkins, McLaughlin, and Daniel (1946) there has been little detail given of the mental state of such patients during the period of recovery. It is the purpose of this communication to describe such a state.

\section{Case Report}

On May 19, 1947, a healthy young man, aged 29 years, was about to undergo the operation of submucous resection in a general hospital in London.

\section{9/5/47 : First day}

9.15 a.m. Nose packed with $1 / 1000$ adrenalin and $10 \%$ cocaine.

10.50 a.m. Anæsthetic begun (pentothal and cyclopropane).

11.00 a.m. $2 \mathrm{~m} .1 / 1000$ adrenalin injected around the nasal septum.

11.04 a.m. Sudden arrest of heart and collapse of patient. Subcostal incision made on left side and cardiac massage carried out.

11.11 a.m. The heart began beating again. The operation was not proceeded with and the patient was returned to the ward. During the next 24 hours the heart stopped four times and the breathing several times. The patient was revived by means of artificial respiration and the administration of oxygen, carbon dioxide, and coramine.

12.45 p.m. Return of cough reflex. Knee jerks present.

1.30 p.m. Rapid onset of generalized tonic spasm of arms and legs. Still unconscious.

3.00 p.m. Arms and legs flaccid. Eyes deviated upwards and to the right. Breathing stertorous. Coma appeared to be deepening.

11.00 p.m. Coma deeper. Respiration laboured. Blood pressure, 135/85 mm. Hg.
20/5/47 : Second day

9.00 a.m. Condition improved. Spontaneous movements of eyes and all four limbs. Reacts to painful stimuli and occasionally to the spoken word.

1.00 p.m. Condition unchanged. Pupils fixed and semi-dilated.

3.00 p.m. Very restless. Answers vaguely to name. Pupils fixed and dilated.

6.00 p.m. Vomited twice. Incontinent of urine and of fæces.

8.00 p.m. Projectile vomiting. Tendon reflexes present and equal. Pupils react to light. He recognizes his brother and sister.

21/5/47 : Third day

9.00 a.m. Improved. Cooperative. He can answer some questions, such as his name, age and address, but he does not know where he is nor why he is here. He sits up in bed and takes fluid by mouth.

9.00 p.m. Very obstreperous and noisy.

11.00 p.m. Has torn out two stitches and the wound is gaping. He keeps getting out of bed and dashing about the ward.

22/5/47 : Fourth day

Very aggressive and resistive to treatment. Attempts were made to keep him sedated by use of soluble phenobarbitone, medinal, and morphia.

23/5/47 : Fifth day

3.25 p.m. Admitted to a mental observation unit. He was quiet on admission but was mentally confused. His general physical condition was good except that the tendon and plantar reflexes were not obtained. He did not know where he was. At one moment he told his correct occupation, but a few minutes later he said he was a sergeant in the Royal Air Force.*

5.00 p.m. Restless, getting out of bed and picking at his bandage, which he finally removes, but he does not interfere with the

* The patient had served in the Royal Air Force during the war and was stationed in Northern Ireland for some time. 
stitches of his wound. He bids the doctor good-morning and then says he must go back to his hotel, which he says is in Belfast, as he is crossing to England tonight. He listens quietly and appears to understand when he is told that he is in hospital and that he must stay in bed, but in a few minutes he seems to have forgotten this and keeps on trying to get out of bed.

9.30 p.m. He is quiet and more amenable. He thinks he has met the doctor before in Ireland, which is not so.

\section{4/5/47 : Sixth day}

He continues to improve. He slept without any sedative drug and is quiet and more lucid. He remembers vaguely without any details that he had been in hospital for an operation on his nose.

25/5/47 : Seventh day

Improvement maintained.

26/5/47 : Eighth day

$\mathrm{He}$ is grossly disorientated and does not remember any of the events leading to his coming here. He has forgotten about the proposed nasal operation. He takes little interest in anything but remains quiet.

\section{7/5/47 : Ninth day}

$\mathrm{He}$ is still disorientated and appears to be childishly contented and pleased at attentions paid to him. He confabulated to a visitor, telling him he had had a breakdown before Christmas and had been in hospital since then.

There are now no abnormal physical signs on examination of the nervous system.

28/5/47 : Tenth day

$\mathrm{He}$ is much improved. He can read newspapers and books and can recall what he has read. He is correctly orientated.

\section{5/6/47 : Eighteenth day}

He remembers going to the general hospital but does not remember the events connected with the proposed operation for 12 hours before and about four days after.

6/6/47 : Nineteenth day

He still has the same degree of amnesia. He appears to be a pleasant, even-tempered young man who accepts the facts that have been explained to him, without any appearance of ill-will. He says that he feels he is now well on the way to recovery.

\section{9/6/47 : Twenty-second day}

Discharged to a convalescent home. On discharge he was lacking in self-confidence and was doubtful that he would ever be fit to resume his former responsible post. (He had been traffic manager in a large firm of machinery manufacturers.) After three 'months' convalescence he went back to work, at first doing routine office work in the accounts office. By degrees he undertook full-time duty, but still in a subordinate position.
The patient was seen again about a year later (27/5/48), when a psychiatric examination was carried out and the following notes were made.

\section{Psychiatric Examination}

Personality.-He has a pleasant, courteous manner and is of good appearance, well dressed and well cared for. He talks well, but his speech is inclined to be stiff and formal, lacking in colloquialisms. He says he was sociable and fond of games, his chief interests being tennis and swimming. He mixed well with both sexes and was good at making and keeping friends. He says he still has these same qualities. He feels that he has less initiative and energy. He tires easily and is still lacking in confidence to resume the same work as before the accident, although he thinks he is improving and that he will eventually be as fit as before. He is now working as assistant to the man who was his assistant before the accident and he seems to be quite satisfied with this arrangement.

Memory.-A questionnaire on recent and remote events revealed no abnormality except that there is a residual amnesia for the events of about 12 hours before and about four days after the accident.

Intelligence.-He is of high intelligence which would appear to have undergone no serious deterioration. $\mathrm{He}$ made the scores noted on the following tests.

Progressive Matrices.-S.G. 2 in 20 minutes.

Koh's Blocks.-Full score, 98 (Vernon's norms).

Kent Oral.-Mental Age 14 plus.

Shipley Hartford Vocabulary and Abstracts.-Class A

Wechsler Bellevue (Verbal).--Intelligence quotient 131

Report from Brother (9/6/48).-_" $\mathrm{He}$ is inclined to be forgetful and his recollection of past events takes longer than normal. He seems older now in his behaviour. This in my view is an improvement. He tires easily and is restless, seldom staying in one place very long. $\mathrm{He}$ seems to lack any definite interest in life which probably accounts for his restlessness. His general health is excellent ; he eats like a horse and sleeps well."

Electroencephalogram.-An electroencephalogram was made on May 25, 1948. The record showed an alpha rhythm at $9-10 \mathrm{c} / \mathrm{s}$. of moderate amplitude which was reduced on opening the eyes. Mental activity also caused a reduction in the alpha rhythm. Activity at 18-22 c/s. of low amplitude was recorded from the frontal areas but most of this was probably of muscle origin. Hyperpnœa caused no obvious change in the record.

Follow-up.-He was seen again on June 3, 1949, and he appeared to have made a good recovery with the exception of the amnesia which remained as before. He had regained most of his former confidence in his ability to do his work and he was considering the possibility of taking up a new post of considerable responsibility.

He now (October 15, 1949) reported that he had asked for an interview with one of the directors of his firm, as the result of which he was offered the post of traffic manager of the firm with his office at the works in the 
country. This was a new post as the traffic manager had up to this time been in London and under the direction of the London manager. In the new position he would be his own master responsible only from time to time to the director.

The patient's manner of talking had quite changed. He was alert and confident, and gave the impression that he was no longer satisfied with a routine subordinate post, but was desirous of having a responsible post requiring initiative and independence.

In January, 1950, he wrote to say that he was facing up to the problems and difficulties of his new post with confidence. On February 1, 1950, his brother reported that he had seen him recently and that he was satisfied that he had made a good recovery. He observed no difference in his personality before and after the accident ; he thought that his brother had regained his former confidence in his ability to do his work, and that he now had the same energy and initiative as before. His relations with other people were still good.

\section{Summary}

A case of heart arrest during anæsthesia is reported with special reference to the mental state during recovery. One year after the accident the patient showed signs suggestive of a mild frontal lobe syndrome. Two years after the accident he appeared to have made a good recovery and his brother could see no change of personality since the illness. There was still amnesia for 12 hours before and four days after the accident.

Thanks are expressed to the County Medical Officer, London County Council, for permission to publish this case ; to Dr. H. Hilton Stewart of Claremont Street Hospital for Nervous Diseases, Belfast, for the electroencephalogram ; and to Dr. R. S. Allison, Physician-incharge, Neurological Department, Royal Victoria Hospital, Belfast, for his help and encouragement in preparing this paper.

\section{REFERENCES}

Bailey, H. (1947). Lancet, 1, 5.

Howkins, J., McLaughlin, C. R., and Daniel, P. (1946). Ibid., 1, 488.

Noble, A. B. (1947). Canad. med. Ass. J., 56, 490.

Sappenfield, R. S., and Adriani, J. (1947). Sth. Med. J., 40, 455 .

\section{INTERNATIONAL FEDERATION OF E.E.G. SOCIETIES}

The International Federation of E.E.G. Societies was founded in the form of an International Committee at a meeting in London in July, 1947. The journal Electroencephalography and Clinical Neurophysiology was established as the organ of the Federation, and working committees were formed. At a second meeting in Paris in 1949 a more formal organization was established in liaison with UNESCO. Correspondence should be addressed to the Secretary (Dr. H. Gastaut), International Federation of Electro-encephalography and Clinical Neurophysiology, 149 Prom. de la Corniche, Marseille, France.

The next meeting of the Federation will be held in the United States in June, 1952.

Correction.-On page 46 of the February issue the reference to Ferner, H. (1940). Z. Anat. EntwGesch., 110, 391, is wrong, and the full correct reference is : Ferner, H. (1949). "Die Trigeminuszisterne und ihre praktische Bedeutung für die Alkoholinjektion in das Gassersche Ganglion ", Nervenarzt, 20, 26.

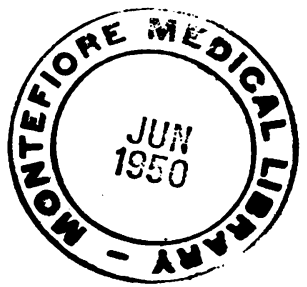

